\title{
openheart Peripheral artery disease and outcomes in patients with acute myocardial infarction
}

\author{
Rubina Attar, ${ }^{\oplus 1,2}$ Axel Wester, ${ }^{1}$ Sasha Koul, ${ }^{1}$ Svend Eggert, ${ }^{2}$ Pontus Andell ${ }^{3}$
}

To cite: Attar R, Wester A, Koul S, et al. Peripheral artery disease and outcomes in patients with acute myocardial infarction. Open Heart 2019;6:e001004. doi:10.1136/ openhrt-2018-001004

Received 3 January 2019 Revised 21 March 2019 Accepted 14 April 2019
Check for updates

(C) Author(s) (or their employer(s)) 2019. Re-use permitted under CC BY-NC. No commercial re-use. See rights and permissions. Published by BMJ.

${ }^{1}$ Cardiology and Clinical Sciences, Lunds Universitet, Lund, Sweden

${ }^{2}$ Cardiology, Aalborg University Hospital, Aalborg, Denmark ${ }^{3}$ Cardiology, Karolinska Institutet, Stockholm, Sweden

Correspondence to Rubina Attar; rubina.attar@ med.lu.se

\section{ABSTRACT}

Aim To describe the population of patients with previously diagnosed peripheral artery disease (PAD) experiencing a myocardial infarction (MI) and to investigate 1-year major adverse cardiac events (MACE: all-cause mortality, reinfarction, stroke and heart failure hospitalisation) following MI.

Background MI patients with PAD constitute a high-risk population with adverse cardiac outcomes. Contemporary real-life data regarding the clinical characteristics of this patient population and clinical event rates following $\mathrm{Ml}$ remain scarce.

Methods This observational study included all MI patients presenting with ST-elevation MI or non-ST-elevation MI between 01 January 2005 and 31 December 2014 with $(n=4213)$ and without $(n=106763)$ a concurrent PAD diagnosis, identified in the nationwide Swedish Websystem for Enhancement and Development of Evidencebased care in Heart disease Evaluated According to Recommended Therapies registry and the National Patient Registry (PAD prevalence: 3.8\%). Cox proportional hazard models were applied to compare the outcome between the two populations.

Results MI patients with PAD were older and more often burdened with comorbidities, such as diabetes, hypertension and previous MI. After adjustments, PAD was significantly associated with higher rates of MACE (HR $1.35,95 \% \mathrm{Cl} 1.27$ to 1.44 ), mortality (HR $1.59,95 \% \mathrm{Cl}$ 1.43 to 1.76 ), reinfarction (HR $1.48,95 \% \mathrm{Cl} 1.32$ to 1.66 ), stroke (HR 1.27, $95 \% \mathrm{Cl} 1.05$ to 1.53), heart failure (HR $1.29,95 \% \mathrm{Cl} 1.20$ to 1.40 ) and bleeding (HR $1.26,95 \% \mathrm{Cl}$ 1.09 to 1.47 ) at 1 year.

Conclusion A concurrent PAD diagnosis was independently significantly associated with higher rates of adverse outcomes following $\mathrm{MI}$ in a nationwide real-life MI population. The low prevalence of PAD compared with previous studies suggests significant underdiagnosing. Future studies should investigate if PAD screening with ankle-brachial index may increase diagnosing and subsequently lead to improved treatment of polyvascular disease

\section{INTRODUCTION SUMMARY}

Peripheral artery disease (PAD) and coronary artery disease (CAD) are clinical manifestations of atherosclerosis involving different vascular beds. It has been established that the more arterial beds affected by atherosclerosis the higher the risk of experiencing a cardiovascular event, such as stroke, myocardial

\section{Key Questions}

What is already known about this subject?

- Previous studies have reported varying prevalences of peripheral artery disease (PAD) in a population with coronary artery disease (CAD), ranging from 8-42\% depending on diagnostic method.

- It is important to identify atherosclerosis in vascular beds other than the coronary arteries, since mortality rates increase with number of arterial beds affected.

What does this study add?

- In this nationwide observational study including 110 976 patients with a myocardial infarction (MI), we found the prevalence of PAD to be $3.8 \%$, far less than previously reported.

- Selected CAD patients with concomitant PAD had increased mortality, reinfarction, stroke, heart failure and bleeding risks.

How might this impact on clinical practice?

- The findings in this study suggests a more interdisciplinary approach when dealing with patients with poly-vascular disease.

- Individuals with known CAD may benefit from PAD screening for early disease detection.

infarction (MI) or death due to cardiovascular causes. ${ }^{1}$ Substantiating this, various studies have shown that MI patients with PAD are a high-risk population that experiences more adverse cardiac outcomes compared with MI patients without PAD. ${ }^{2-7}$ The concurrent prevalence of PAD in patients with $\mathrm{MI}$ is uncertain; several studies have reported conflicting numbers ranging from $8 \%$ to $42 \%$ depending on diagnostic definition and methods. ${ }^{4589}$

The interest in the role of PAD in patients with $\mathrm{CAD}$ has lately been rising. A major contributor has been the Cardiovascular Outcomes for People Using Anticoagulation Strategies (COMPASS) trial, which showed that low-dose rivaroxaban two times per day plus aspirin decreased major adverse cardiac events (MACE) compared with rivaroxaban or aspirin alone in patients with PAD. ${ }^{10}$

Nonetheless, contemporary real-life data from large samples regarding the clinical 
characteristics of MI patients with PAD remain scarce. We aimed to describe the baseline and clinical characteristics in the population of patients with PAD experiencing an MI, to analyse adverse outcomes following MI, and to investigate prescriptions of guideline-based secondary preventive medical therapies in this patient group using a nationwide contemporary population-based registry.

\section{METHODS}

\section{Study sample}

This observational follow-up study included all patients presenting with an ST-segment elevation MI (STEMI) or non-STEMI (NSTEMI) between 01 January 2005 and 31 December 2014 with and without a concurrent PAD diagnosis. The patients were identified and included from the Swedish Web-system for Enhancement and Development of Evidence-based care in Heart disease Evaluated According to Recommended Therapies registry (SWEDEHEART). PAD was defined as having an electronic healthcare record of ICD-codes (10th version: I70-73; ninth version: 440-443) before baseline. In total, 4213 MI patients with a previous PAD diagnosis (prevalence: 3.8\%) were compared with 106 763 MI patients without a previous PAD diagnosis.

\section{National registries}

SWEDEHEART consists of several subregistries and the ones used in this study includes the Register of Information and Knowledge About Swedish Heart Intensive Care Admissions, which has information from coronary care units throughout the country, and the Swedish Coronary Angiography and Angioplasty Registry ${ }^{11}$ that provides data from all catheterisation labs in Sweden. The merged SWEDEHEART registry simplifies the transferring of information between hospitals and avoids repeated entering of data in different registries as well as making high-quality data available for research purposes. The registry contains clinical information on all patients in Sweden who are treated at coronary care units, who undergo coronary angiography and percutaneous coronary interventions. Data include risk factors, past medical history, treatment during hospitalisation, discharge medications and final diagnoses. SWEDEHEART can also be connected to other registries using the unique personal number given to all Swedish citizens. We linked SWEDEHEART with the National Population Register to assess vital status and date of death, and the National Patient Registry to ascertain PAD status and comorbidities through ICD-10 diagnostic codes. The personal numbers are replaced by a serial number to ensure anonymity. ${ }^{11}$

\section{Endpoints}

The primary endpoint was 1-year MACE defined as all-cause mortality, rehospitalisation for MI, hospitalisation for stroke and hospitalisation for heart failure. Secondary endpoints were individual components of the primary composite endpoint at 1 year and hospitalisation for major bleeding (fatal, cerebral or bleeding requiring surgery or transfusion, defined by ICD-9 (430, 431, 432, 578, 285B, 456A, 531A, 531C, 531E, 531G，532A，532C，532E，532G，533A，533C, 533E, 533G, 534A, 534C, 534E, 534G and 569D) and ICD-10 (I60, I61, I62, D629, I850, K226, K250, K252, K254, K256, K260, K262, K264, K266, K270, K272, K274, K276, K280, K282, K284, K286, K290, K625, K920, K921 and K922) codes).

\section{Statistical analysis}

Continuous variables are expressed as means with SD and differences between groups were compared using Student's t-test. Categorical variables are expressed as counts and percentages and differences between groups were analysed using the $\chi^{2}$ test. Endpoints in patients with and without PAD were calculated using the Kaplan-Meier survival estimator and log-rank tests were used to calculate the differences between the groups. For reinfarction, we used a 30-day blanking period post-discharge to avoid early follow-up visits misclassified as new MIs. HRs with 95\% CIs were calculated using univariable and multivariable Cox proportional hazard models. Multivariable models were adjusted for potential confounders in three models. The first model adjusted for age and sex. The second model adjusted for age, sex and comorbidities including atrial fibrillation, CAD presentation (angiographic findings and presenting symptoms), diabetes, smoking, hypertension, stroke, MI, previous percutaneous coronary intervention (PCI), previous coronary artery bypass graft (CABG), heart failure, renal failure, chronic obstructive pulmonary disease and previous bleeding. The final model adjusted for all of the above and additionally guideline-based medical therapy (dual antiplatelet therapy (DAPT), ACE inhibitor or angiotensin II receptor blocker (ACEi/ARB), beta-blockers and statins) as well as management with PCI and CABG and only included hospital survivors. The count and percentage of missing data were reported for each variable. All $\mathrm{p}$ values were two-tailed and a value of $<0.05$ was considered statistically significant. All analyses were performed using STATA V.14.0 and SPSS V.25.

\section{RESULTS \\ Patient characteristics}

Baseline characteristics for MI patients with and without $\mathrm{PAD}$ are outlined in table 1 . The prevalence of PAD was $3.8 \%(4213 / 110$ 976). Patients with PAD were older (mean 73 vs 67 years, $\mathrm{p}<0.001$ ), and had a heavier smoking history (more previous smokers and current smokers $)(p<0.001)$. Moreover, a larger burden of comorbidities was seen in PAD patients, with higher prevalence's of diabetes, hypertension, hyperlipidaemia, previous MI, previous stroke, heart failure, renal failure, chronic obstructive pulmonary disease and previous bleeding (all $\mathrm{p}<0.001$ ). 
Table 1 Baseline characteristics for all MI patients with and without PAD between 2005 and 2014 in Sweden

\begin{tabular}{|c|c|c|c|c|c|}
\hline & $\begin{array}{l}\text { PAD } \\
(n=4213)\end{array}$ & $\begin{array}{l}\text { Non-PAD } \\
(n=106763)\end{array}$ & $\begin{array}{l}\text { Entire } \\
\text { population } \\
(n=110976)\end{array}$ & Missing n (\%) & $P$ value \\
\hline $\begin{array}{l}\mathrm{n}(\%) \\
\text { Age (years) mean (SD) }\end{array}$ & $\begin{array}{l}4213(3.8) \\
73.1(8.9)\end{array}$ & $\begin{array}{l}106521(96.2) \\
67.4(11.5)\end{array}$ & $\begin{array}{l}110734 \\
67.6(11.5)\end{array}$ & $242(0.2)$ & $<0.001$ \\
\hline \multicolumn{6}{|l|}{$\operatorname{Sex} n(\%)$} \\
\hline Male & $2801(66.5)$ & $73183(68.6)$ & 75984 (68.5) & 0 & 0.005 \\
\hline Female & $1412(33.5)$ & $33580(31.5)$ & $34992(31.5)$ & & \\
\hline \multicolumn{6}{|l|}{ Smoking status n (\%) } \\
\hline Never & $978(23.2)$ & $41055(38.5)$ & $42033(37.9)$ & $5918(5.3)$ & $<0.001$ \\
\hline Ex-smoker & $1825(42.3)$ & 33653 (31.5) & $35478(32.0)$ & & \\
\hline (>1 month) Smoker & $1104(26.2)$ & $26443(24.8)$ & $27547(24.8)$ & & \\
\hline Diabetes n (\%) & $1584(37.7)$ & $22077(20.7)$ & $23664(21.3)$ & 0 & $<0.001$ \\
\hline Hypertension n (\%) & $3543(84.1)$ & $59561(55.8)$ & $63104(56.9)$ & $1241(1.2)$ & $<0.001$ \\
\hline Hyperlipidaemia n (\%) & $2286(54.3)$ & $24025(22.5)$ & $26311(23.7)$ & $1141(1.0)$ & $<0.001$ \\
\hline Previous myocardial infarction $\mathrm{n}(\%)$ & $1791(42.5)$ & $17072(16.0)$ & $18863(17.0)$ & $1692(1.6)$ & $<0.001$ \\
\hline Previous PCI n (\%) & $617(14.7)$ & $6431(6.0)$ & $7048(6.4)$ & $162(0.2)$ & $<0.001$ \\
\hline Previous CABG n (\%) & $825(19.6)$ & $4940(4.6)$ & $5765(5.2)$ & $92(0.1)$ & $<0.001$ \\
\hline $\begin{array}{l}\text { Previous stroke } \\
\mathrm{n}(\%)\end{array}$ & $911(21.6)$ & $8360(7.8)$ & $9271(8.4)$ & $2930(2.7)$ & $<0.001$ \\
\hline Heart failure $n(\%)$ & $786(18.7)$ & $4778(4.5)$ & $5564(5.0)$ & 0 & $<0.001$ \\
\hline Renal failure $\mathrm{n}(\%)$ & $445(10.6)$ & $1596(1.5)$ & $2041(1.8)$ & 0 & $<0.001$ \\
\hline Dialysis n (\%) & $124(2.9)$ & $356(0.3)$ & $480(0.4)$ & & $<0.001$ \\
\hline COPD n (\%) & $617(14.7)$ & $5378(5.0)$ & $5995(5.4)$ & 0 & $<0.001$ \\
\hline Previous bleeding $\mathrm{n}(\%)$ & $427(10.1)$ & $4053(3.8)$ & $4480(4.0)$ & 0 & $<0.001$ \\
\hline
\end{tabular}

CABG, coronary artery bypass graft; COPD, chronic obstructive pulmonary disease; MI, myocardial infarction; PAD, peripheral artery disease;

$\mathrm{PCl}$, percutaneous coronary intervention.

\section{Clinical findings and presentation}

The laboratory findings, clinical presentations, ECG changes and procedural characteristics during hospitalisation for MI patients with and without PAD are outlined in table 2. The laboratory findings showed that patients with MI and PAD had higher levels of $\mathrm{C}$ reactive protein and creatinine and lower levels of haemoglobin. Patients with PAD were more likely to present with dyspnoea compared with patients without PAD. They also had slightly lower blood pressure and higher heart rate compared with the non-PAD group at presentation. Moreover, the PAD group experienced more NSTEMI than STEMI, and their presenting ECG showed more atrial fibrillation or flutter and more bundle branch block. PAD patients had more severe CAD with more multivessel and left main disease on the angiogram and they had lower left ventricular function. The PAD group were less often revascularised with PCI or CABG compared with the non-PAD group. All differences presented have a $\mathrm{p}$ value of $<0.05$.

\section{Discharge medications}

Patients with MI and PAD were less frequently discharged with DAPT as seen in table 3. In contrast, these patients were more often discharged with anticoagulants, such as warfarin, as atrial fibrillation was more common. There were no clinically relevant differences in prescriptions of ACEi/ARB, beta-blockers or statins. MI and PAD patients more often received digoxin and diuretics.

\section{Clinical endpoints}

The primary endpoint of 1-year MACE occurred significantly more frequently in the PAD group compared with the non-PAD group with an unadjusted HR of 2.65 (95\% CI 2.52 to 2.78 ) (table 4 and figure 1). Following adjustment for age and sex, the HR decreased to 2.09 (95\% CI 1.98 to 2.20). Further adjustment for comorbidities decreased the HR to 1.31 (95\% CI 1.21 to 1.42). Adjustments for guideline-based medical therapy and management with PCI and CABG increased the HR to 1.35 (95\% CI 1.27 to 1.44 ). The adjusted secondary endpoints, mortality (HR $1.59,95 \%$ CI 1.43 to 1.76 ), reinfarction (HR 1.48, 95\% CI 1.32 to 1.66 ), stroke (HR 1.27, 95\% CI 1.05 to 1.53), heart failure (HR 1.29, 95\% CI 1.20 to 1.40 ) and bleeding rates (HR 1.26, 95\% CI 1.09 to 1.47 ), were significantly higher in the PAD population (table 4). 
Table 2 Laboratory findings, clinical presentation, ECG changes and procedures in the different MI groups during hospitalisation

\begin{tabular}{|c|c|c|c|c|c|}
\hline & PAD & Non-PAD & Entire population & Missing n (\%) & $P$ value \\
\hline Creatinine mean (SD) & $120.0(106.0)$ & $88.6(47.0)$ & $90.0(50.8)$ & $4878(4.4)$ & $<0.001$ \\
\hline Haemoglobin mean (SD) & $132.6(17.9)$ & $140.7(15.7)$ & $140.4(15.9)$ & $16228(14.6)$ & $<0.001$ \\
\hline CRP mean (SD) & $28.4(50.1)$ & $18.0(39.6)$ & $18.3(40.1)$ & $13362(12.0)$ & $<0.001$ \\
\hline \multicolumn{6}{|l|}{ Coronary marker levels mean (SD) } \\
\hline Troponin T & $125.4(852)$ & $85.4(675)$ & $86.8(682)$ & $79943(72.0)$ & 0.056 \\
\hline Troponin I & $23.5(189)$ & $21.5(136)$ & $21.6(139)$ & $68354(61.2)$ & 0.571 \\
\hline Systolic blood pressure mean (SD) & $145.3(30.8)$ & $148.4(29.2)$ & $148.3(29.3)$ & $5831(5.3)$ & $<0.001$ \\
\hline Diastolic blood pressure mean (SD) & $80.6(17.2)$ & $85.25(17.1)$ & $85.3(17.2)$ & $8766(7.9)$ & $<0.001$ \\
\hline Heart rate mean (SD) & $83.1(24.3)$ & $78.7(21.6)$ & $78.9(21.7)$ & $970(0.9)$ & $<0.001$ \\
\hline \multicolumn{6}{|l|}{ Presenting symptoms n (\%) } \\
\hline Chest pain & $3465(82.3)$ & $94583(88.6)$ & $98048(88.4)$ & $1203(1.1)$ & $<0.001$ \\
\hline Dyspnoea & $378(9.0)$ & $4392(4.1)$ & $4770(4.3)$ & & \\
\hline Cardiac arrest & $58(1.4)$ & $1325(1.2)$ & $1383(1.3)$ & & \\
\hline Other & $277(6.6)$ & $5295(5.0)$ & $5572(5.0)$ & & \\
\hline \multicolumn{6}{|l|}{ Infarct type n (\%) } \\
\hline STEMI & $1261(29.9)$ & $43505(40.8)$ & $44766(40.3)$ & $396(0.4)$ & $<0.001$ \\
\hline NSTEMI & $2940(69.8)$ & $62874(58.8)$ & $65814(59.3)$ & & \\
\hline \multicolumn{6}{|l|}{ ECG: ST-segment n (\%) } \\
\hline Normal & $676(16.1)$ & $22161(20.8)$ & $22837(20.6)$ & $12915(11.6)$ & $<0.001$ \\
\hline ST-elevation & $1193(28.3)$ & $41644(39.0)$ & $42837(38.6)$ & & \\
\hline ST-depression & $1259(29.9)$ & $20743(19.4)$ & $22002(19.3)$ & & \\
\hline Pathological T-wave & $384(9.1)$ & $10001(9.4)$ & $10385(9.4)$ & & \\
\hline \multicolumn{6}{|l|}{ ECG: rhythm n (\%) } \\
\hline Sinus & 3470 (82.4) & $95863(89.8)$ & $99333(89.5)$ & $3740(3.4)$ & $<0.001$ \\
\hline Atrial fibrillation/flutter & $545(12.9)$ & $7358(6.9)$ & $7903(7.1)$ & & \\
\hline \multicolumn{6}{|l|}{ ECG: QRS n (\%) } \\
\hline Normal & $2464(58.5)$ & $72427(67.8)$ & 74891 (67.5) & $15317(13.8)$ & $<0.001$ \\
\hline LBBB & $315(7.5)$ & $4369(4.1)$ & $4684(4.2)$ & & \\
\hline RBBB & $227(5.4)$ & $4046(3.8)$ & $4273(3.9)$ & & \\
\hline Pathological Q-wave & $479(11.4)$ & $11332(10.6)$ & $11811(10.6)$ & & \\
\hline \multicolumn{6}{|l|}{ Left ventricular function n (\%) } \\
\hline Normal $\geq 50 \%$ & $1454(34.5)$ & $50705(47.5)$ & $52159(47.0)$ & $22778(20.5)$ & $<0.001$ \\
\hline Slightly decreased $40 \%-49 \%$ & $780(18.5)$ & $18770(17.6)$ & $19550(17.6)$ & & \\
\hline Moderately decreased 30\%-39\% & $576(13.7)$ & $10991(10.3)$ & $11567(10.4)$ & & \\
\hline Severely decreased $<30 \%$ & $350(8.3)$ & $4572(4.3)$ & $4922(4.4)$ & & \\
\hline PCl n (\%) & $2846(67.6)$ & $82397(77.2)$ & $85243(76.8)$ & 0 & $<0.001$ \\
\hline CABG n (\%) & $280(6.7)$ & $4247(4.9)$ & $5527(5.0)$ & 0 & $<0.001$ \\
\hline \multicolumn{6}{|l|}{ Angiographic findings } \\
\hline Normal/atheromatosis & $208(4.9)$ & $9708(9.1)$ & $9916(8.9)$ & $646(0.6)$ & $<0.001$ \\
\hline 1-vessel, no LMD & $919(21.8)$ & $42138(39.5)$ & $43057(38.8)$ & & \\
\hline 2-vessel, no LMD & $970(23.0)$ & $26096(24.4)$ & $27066(24.4)$ & & \\
\hline 3-vessel, no LMD & $1311(31.1)$ & $20608(19.3)$ & 21919 (19.8) & & \\
\hline LMD & $756(17.9)$ & $7616(7.1)$ & $8372(7.5)$ & & \\
\hline
\end{tabular}

CABG, coronary artery bypass graft; CRP, C reactive protein;LBBB, left bundle branch block; LMD, left main disease; MI, myocardial infarction; NSTEMI, non-ST-segment elevation MI;PAD, peripheral artery disease; PCI, percutaneous coronary intervention;RBBB, right bundle branch block; STEMI, ST-segment elevation MI. 


\begin{tabular}{|c|c|c|c|c|c|}
\hline & PAD & Non-PAD & Entire population & Missing $\mathbf{n}(\%)$ & P value \\
\hline DAPT n (\%) & 3050 (77.2) & 87052 (83.9) & $90102(83.7)$ & $294(0.3)$ & $<0.001$ \\
\hline Aspirin n (\%) & 3686 (93.3) & 99068 (93.3) & 102754 (95.4) & $134(0.1)$ & $<0.001$ \\
\hline P2Y12 inhibitor n (\%) types & $3223(81.5)$ & 89907 (86.7) & $93130(86.5)$ & $160(0.2)$ & $<0.001$ \\
\hline Clopidogrel & $2696(68.2)$ & $71170(68.6)$ & $73866(68.6)$ & & \\
\hline Prasugrel & $30(0.8)$ & $1612(1.6)$ & $1642(1.5)$ & & \\
\hline Ticagrelor & $473(12.0)$ & $16609(16.0)$ & $17082(15.9)$ & & \\
\hline $\begin{array}{l}\text { Anticoagulants } n(\%) \\
\text { types }\end{array}$ & $369(9.3)$ & $3777(3.6)$ & $4146(3.9)$ & $725(0.7)$ & $<0.001$ \\
\hline Warfarin & $366(9.3)$ & $3700(3.6)$ & $4066(3.8)$ & & \\
\hline Dabigatran & $2(0.05)$ & $46(0.04)$ & $48(0.04)$ & & \\
\hline Rivaroxaban & $1(0.03)$ & $14(0.01)$ & $15(0.01)$ & & \\
\hline ACEi/ARB n (\%) & $3044(77.0)$ & 78897 (76.1) & $81942(76.1)$ & $1465(1.4)$ & 0.172 \\
\hline Beta blockers n (\%) & 3531 (89.3) & $93873(90.5)$ & $97404(90.5)$ & $149(0.1)$ & 0.022 \\
\hline Calcium antagonists $\mathrm{n}(\%)$ & $1073(27.1)$ & 13797 (13.3) & 14870 (13.8) & $170(0.2)$ & $<0.001$ \\
\hline Digitalis n (\%) & $151(3.8)$ & $1852(1.8)$ & $2003(1.9)$ & $151(0.1)$ & $<0.001$ \\
\hline Diuretics n (\%) & $1791(45.3)$ & $23446(22.6)$ & $25237(23.4)$ & $159(0.2)$ & $<0.001$ \\
\hline Statins n (\%) & 3556 (90.0) & 96649 (93.2) & 100205 (93.1) & $161(0.2)$ & $<0.001$ \\
\hline $\begin{array}{l}\text { Other lipid lowering agents } \\
\text { n (\%) types }\end{array}$ & $122(3.1)$ & $1289(1.2)$ & $1411(1.3)$ & $1193(1.1)$ & $<0.001$ \\
\hline Ezetimibe & $95(2.4)$ & $978(0.9)$ & $1073(1.0)$ & & \\
\hline Fibrates & $13(0.3)$ & $156(0.2)$ & $169(0.2)$ & & \\
\hline
\end{tabular}

ACEi, ACE inhibitor; ARB, angiotensin II receptor blocker; DAPT, dual antiplatelet therapy (aspirin and P2Y12 inhibitor);PAD, peripheral artery disease.

\section{DISCUSSION}

To the best of our knowledge, this is the largest registry study to date investigating the baseline and in-hospital characteristics including procedures, discharge medication as well as 1-year MACE following MI in a population with established PAD. Our main findings were significant associations between PAD and higher 1-year rates of MACE, mortality, reinfarction, stroke, heart failure and bleeding following MI. After adjustments for baseline differences including age, comorbidities and guideline-based secondary preventive medical therapies, the HR was lowered but independent statistically significant associations between PAD and higher occurrence of all endpoints

\begin{tabular}{|c|c|c|c|c|c|c|}
\hline \multirow[b]{2}{*}{ End points } & \multicolumn{2}{|c|}{ Kaplan-Meier event rates (\%) } & \multirow{2}{*}{$\begin{array}{l}\text { Unadjusted HR } \\
(95 \% \mathrm{Cl})\end{array}$} & \multicolumn{3}{|c|}{ Adjusted HR (95\% Cl) } \\
\hline & PAD & Non-PAD & & Model 1 & Model 2 & Model 3 \\
\hline MACE & $0.647(35.3)$ & $0.852(14.8)$ & 2.65 (2.52 to 2.78$)^{\star}$ & $2.09(1.98 \text { to } 2.20)^{*}$ & 1.31 (1.21 to 1.42$)^{\star}$ & 1.35 (1.27 to 1.44$)^{*}$ \\
\hline Mortality & $0.807(19.3)$ & $0.934(6.6)$ & $3.24(3.00 \text { to } 3.50)^{*}$ & $2.38(2.21 \text { to } 2.57)^{\star}$ & $1.69(1.48 \text { to } 1.91)^{\star}$ & $1.59(1.43 \text { to } 1.76)^{\star}$ \\
\hline Reinfarction & $0.893(10.7)$ & $0.959(4.1)$ & 2.65 (2.39 to 2.94$)^{*}$ & $2.24(2.02 \text { to } 2.49)^{\star}$ & $1.23(1.05$ to 1.44$) \dagger$ & $1.48(1.32 \text { to } 1.66)^{\star}$ \\
\hline Stroke & $0.959(4.1)$ & $0.982(1,8)$ & $2.38(2.01 \text { to } 2.80)^{*}$ & $1.86(1.57 \text { to } 2.20)^{\star}$ & $1.39(1.08$ to 1.79$) \dagger$ & 1.27 (1.06 to 1.53$) \dagger$ \\
\hline Heart failure & $0.778(22.2)$ & $0.913(8.7)$ & $2.73(2.55 \text { to } 2.94)^{*}$ & $2.1(2.08 \text { to } 2.46)^{\star}$ & $1.21(1.09 \text { to } 1.35)^{*}$ & $1.29(1.20 \text { to } 1.40)^{\star}$ \\
\hline Bleeding & $0.939(6.1)$ & $0.971(2.9)$ & $2.08(1.81 \text { to } 2.38)^{\star}$ & $1.72(1.50 \text { to } 1.98)^{\star}$ & $1.25(1.01$ to 1.56$) \dagger$ & 1.26 (1.09 to 1.47$) \dagger$ \\
\hline
\end{tabular}

Model 1: adjusted for age and sex.

Model 2: adjusted for age, sex, smoking and comorbidities (including previous $\mathrm{PCl}$ and $\mathrm{CABG}$ ).

Model 3: adjusted for age, sex, smoking, comorbidities, guideline-based therapy (DAPT), ARB/ACEi, beta blockers and statins, and management with $\mathrm{PCl}$ and $\mathrm{CABG}$.

${ }^{*} \mathrm{P}<0.001$.

$\dagger \mathrm{P}<0.05$.

ACEi, ACE inhibitor; ARB, angiotensin II receptor blocker; CABG, coronary artery bypass graft; DAPT, dual antiplatelet therapy (aspirin and $\mathrm{P} 2 \mathrm{Y} 12$ inhibitor); MACE, major adverse cardiac events; MI, myocardial infarction; PAD, peripheral artery disease; PCI, percutaneous coronary intervention. 
A
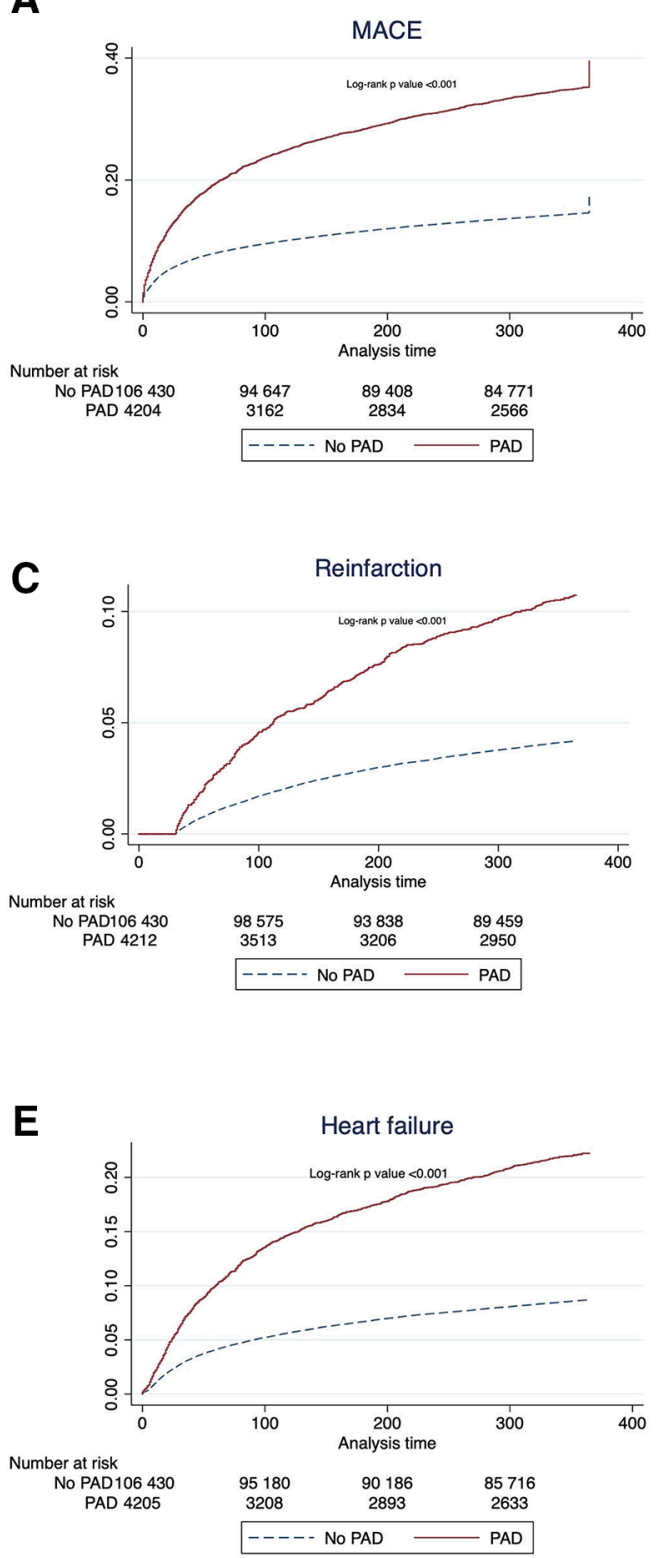

B
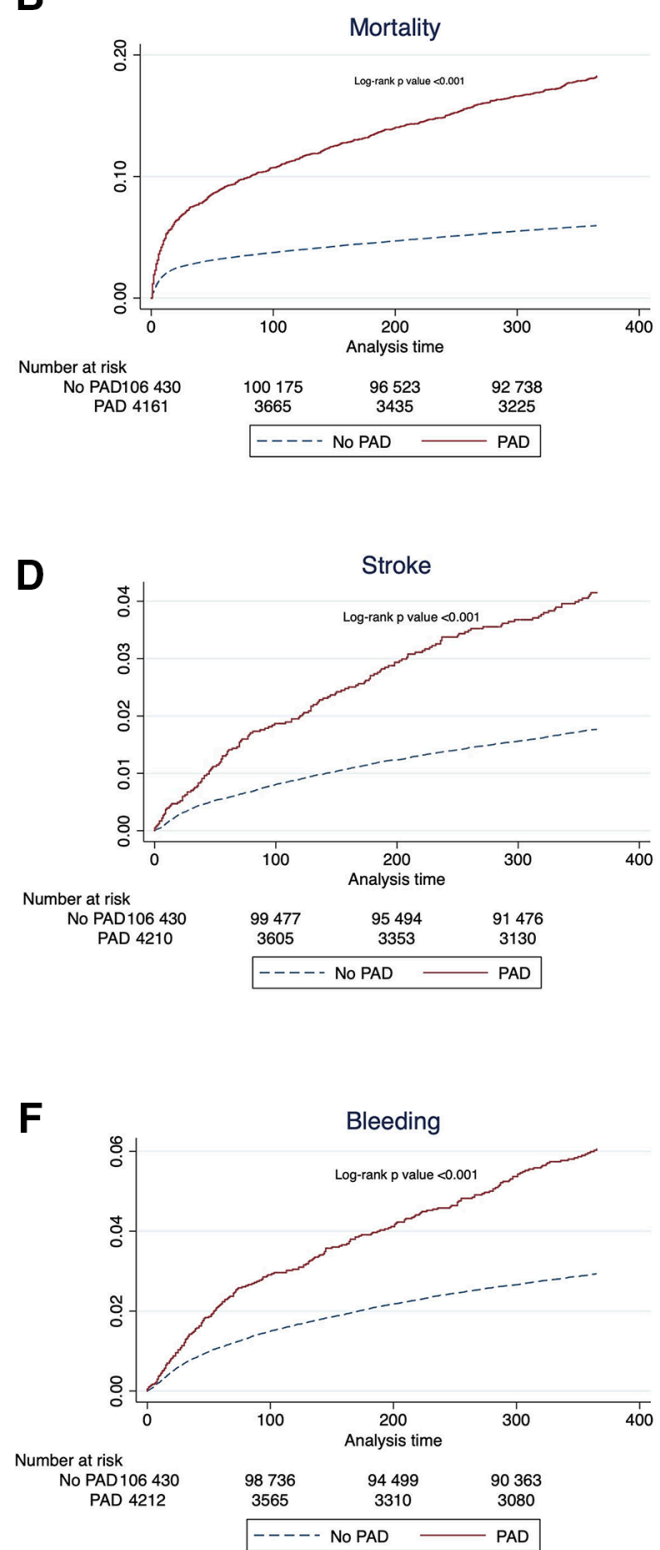

Figure 1 (A-F) Kaplan-Meier survival curves showing the crude 1-year estimates of MACE (mortality, reinfarction, stroke and heart failure), mortality, reinfarction, stroke, heart failure and bleeding rates in an MI population with and without PAD. MACE, major adverse cardiac events; MI, myocardial infarction; PAD, peripheral artery disease.

remained, indicating a high risk accompanied with PAD after MI.

\section{Patient characteristics and clinical presentation}

The prevalence of previously diagnosed PAD in the MI population was $3.8 \%$ in our study, which is lower than what previous studies have reported. ${ }^{48} 89$ Two other studies found the PAD prevalence to be $8.2 \%$ and $13.5 \%$ in study populations of 28771 and 4480 subjects, respectively, were relatively small-scaled compared with our study population $(\mathrm{n}=110976)$. The highest prevalence of $40 \%{ }^{8}$ and $42 \%^{9}$ were found in even smaller studies with 100 and 952 subjects correspondingly. The latter studies were the only studies that defined PAD by measuring the ankle-brachial index of the subjects in the clinical settings. The large differences between symptomatic PAD and PAD defined by screening with ankle-brachial index are likely explained by the relatively long subclinical asymptomatic phase of PAD before the disease manifests itself clinically. A systematic review by Fowkes et al, ${ }^{12}$ pooling a total of 112027 participants, found the prevalence of PAD in the age range between 55 and 79 years to be roughly $9.5 \%$. Taken together, the relatively low PAD prevalence in our study reflects symptomatic PAD that has led to a clinical diagnosis, which is vastly different from subclinical PAD.

We found that patients with PAD had more cardiac risk factors, such as smoking, hypertension, hyperlipidaemia and diabetes, and were generally more comorbid, which is in accordance with previous 
research. ${ }^{278}$ A slightly lower blood pressure was seen in the PAD population; however, since blood pressure was measured peripherally, there is a possibility of false low levels due to subclavian disease in this population. Patients with PAD had higher rates of previous PCI and CABG at baseline and higher rates of CABG but lesser rates of PCI during MI hospitalisation, indicating more advanced coronary heart disease. This is further corroborated by the angiographic findings with more multivessel and left main disease in the PAD population. Our results are supported by a study that found PAD associated with more previous revascularisations. ${ }^{2}$ Further supporting our study, results from the OPUSTIMI study showed that PAD patients more often had severe $\mathrm{CAD}$ and subsequently underwent more CABG compared with PCI. ${ }^{7}$

\section{Discharge medications}

The PAD population was less likely to be treated with DAPT at discharge, but they were more often prescribed warfarin in line with an increased prevalence of atrial fibrillation. Newer studies have implicated that antithrombotic medications, such as ticagrelor and clopidogrel, could be advantageous as supplementing therapies in reducing the risk of cardiovascular events in patients with PAD. ${ }^{10} 14$ The COMPASS PAD trial ${ }^{10}$ concluded, for the first time, the use of rivaroxaban $(2.5 \mathrm{mg}$ two times per day) and aspirin as superior treatment compared with aspirin alone with reduced rates of adverse cardiac events. Another recent antithrombotic treatment alternative is prolonged treatment with low-dose ticagrelor (60 $\mathrm{mg}$ two times per day), which has had promising results published with regard to MI patients with concomitant PAD. ${ }^{13}$ Yet again, these studies were published after our study period and thus, the indications were not approved during our study's time frame.

\section{Endpoints}

A prospective study by Grenon et $a t^{2}$ including 2018 patients with stable CAD concluded an HR of $1.8(95 \%$ CI 1.2 to 2.7) of death and an HR of 1.7 (95\% CI 1.0 to 2.9) for cardiovascular events for MI patients with $P A D$ compared with MI patients without PAD. In our study, the corresponding HRs were 1.6 and 1.4, respectively. The difference is likely explained by the different definitions of cardiovascular events compared with our term MACE. Cardiovascular events in the mentioned study were defined as stroke, transient ischaemic attack, heart failure, MI, revascularisation and death. Furthermore, their adjustment model included race, self-reported history of PAD, inflammatory biomarkers, glycaemic control and health behaviours. Various other studies confirm the increased mortality seen in our study: a follow-up study by Dinser et $a l^{15}$ investigating 4307 patients with incident acute myocardial infarction (AMI) found the mortality HR (follow-up 5.7 years) to be 1.70 (95\% CI 1.35 to 2.13 ) in the PAD population. Moreover, a study consisting of
4480 patients hospitalised for AMI by Spencer et at found a 1-year mortality OR of 2.00 (95\% CI 1.58 to 2.52).

The association between PAD and stroke has previously been described ${ }^{16}$ and our results corroborate this link, suggesting that the more arterial beds affected the more likely it is that an additional atherosclerotic vascular event will occur.

Patients with PAD had a higher risk of being hospitalised for heart failure following MI. In accordance with our results, a meta-analysis established PAD as an independent predictor of adverse outcomes in patients with heart failure following MI. ${ }^{4}$ Both PAD and heart failure are associated with a high morbidity burden. As previously shown, patients with heart failure have a higher prevalence of PAD and present with worse clinical outcomes. ${ }^{17}$ The treatment of PAD also includes exercise, ${ }^{18}$ which can present as a challenge in patients with heart failure due to decreased exercise capacity. ${ }^{19}$ Thus, this vulnerable population with three severe diagnoses, PAD, MI and heart failure, represent a particularly challenging clinical scenario.

A study by Baumann $e t a t^{20}$ investigating the bleeding risk profile and HAS-BLED scores found that patients with PAD had higher risk of bleeding complications compared with the general population. We observed the same pattern in our population. Ischaemic risk and bleeding risk often increase in parallel, which our study also suggests is the case in PAD.

\section{Clinical implication}

MI patients with concomitant PAD are undoubtedly a high-risk population with a high prevalence of cardiac risk factors, challenging comorbidities and more severe $\mathrm{CAD}$. There is an urgent need of a more interdisciplinary approach when dealing with this patient group. In the new guidelines of PAD management, it is pointed out that patients with CAD should be considered for PAD screening. After highlighting the various different PAD prevalences reported in our and others' studies, we agree that PAD screening should be considered in selected patients with a high likelihood of subclinical PAD in order to diagnose the disease early, and subsequently optimally tailor the treatment and provide these patients with newer efficacious medical treatment alternatives.

\section{Limitations}

All patients in our study have previously received an electronic code of PAD and this study, therefore, only entails those with a diagnosis of clinically manifested PAD. Some patients may have been excluded in the study due to various reasons relating to known limitations of registry-based studies. These include, but are not limited to, subclinical disease and underdiagnosis, patients solely managed in the primary care setting and misclassifications of ICD diagnosis codes. Accordingly, we did not have data on the severity of PAD in the population as we had no information on ankle-brachial indexes or other PAD related measurements. 


\section{CONCLUSION}

In this contemporary nationwide population-based study, MI patients with concurrent PAD constituted a high-risk population that was independently and significantly associated with higher risks of MACE, all-cause mortality, reinfarction, stroke, heart failure and bleeding after MI. These patients remain a challenging patient population and there is an urgent need of a more interdisciplinary approach to improve the management of these patients. Moreover, the prevalence of PAD in this study was low compared with previous research. Future studies should investigate if PAD screening with ankle-brachial index may combat underdiagnosing, which subsequently could lead to more patients being treated with novel efficacious treatments to alleviate the increased adverse outcomes of polyvascular disease.

Contributors RA, SK and PA devised the main conceptual ideas and designed the study. RA developed the analysis plan, performed the data collection and statistical analyses as well as interpretation of the results, which SK, PA, AW and SE also contributed to. RA wrote the manuscript. SK, PA, AW and SE provided feedback and helped to shape the article. PA provided firsthand guidance throughout and critical revision of the article. All authors approved the final version of the article to be published.

Funding This study was supported by a grant from the Märta Winkler Foundation. Competing interests None declared.

Patient consent for publication Not required.

Ethics approval This study was approved by the Swedish Central Ethics Committee, DNR: 2019-01458.

Provenance and peer review Not commissioned; externally peer reviewed.

Data availability statement All data relevant to the study are included in the article or uploaded as supplementary information.

Open access This is an open access article distributed in accordance with the Creative Commons Attribution Non Commercial (CC BY-NC 4.0) license, which permits others to distribute, remix, adapt, build upon this work non-commercially, and license their derivative works on different terms, provided the original work is properly cited, appropriate credit is given, any changes made indicated, and the use is non-commercial. See: http://creativecommons.org/licenses/by-nc/4.0/.

\section{REFERENCES}

1. Bhatt DL, Peterson ED, Harrington RA, et al. Prior polyvascular disease: risk factor for adverse ischaemic outcomes in acute coronary syndromes. Eur Heart J 2009;30:1195-202.

2. Grenon SM, Vittinghoff E, Owens CD, et al. Peripheral artery disease and risk of cardiovascular events in patients with coronary artery disease: insights from the heart and soul study. Vasc Med 2013;18:176-84.
3. Beckman JA, Preis O, Ridker PM, et al. Comparison of usefulness of inflammatory markers in patients with versus without peripheral arterial disease in predicting adverse cardiovascular outcomes (myocardial infarction, stroke, and death). Am J Cardiol 2005;96:1374-8.

4. Inglis SC, Bebchuk J, Al-Suhaim SA, et al. Peripheral artery disease and outcomes after myocardial infarction: an individual-patient metaanalysis of 28,771 patients in Capricorn, EPEHESUS, OPTIMAAL and VALIANT. Int J Cardiol 2013;168:1094-101.

5. Spencer FA, Lessard D, Doubeni C, et al. Treatment practices and outcomes of patients with established peripheral arterial disease hospitalized with acute myocardial infarction in a community setting. Am Heart J 2007;153:140-6.

6. Golomb BA, Dang TT, Criqui MH. Peripheral arterial disease: morbidity and mortality implications. Circulation 2006;114:688-99.

7. Cotter G, Cannon CP, McCabe $\mathrm{CH}$, et al. Prior peripheral arterial disease and cerebrovascular disease are independent predictors of adverse outcome in patients with acute coronary syndromes: are we doing enough? Results from the Orbofiban in patients with unstable coronary Syndromes-Thrombolysis in myocardial infarction (OPUSTIMI) 16 study. Am Heart J 2003;145:622-7.

8. Dieter RS, Tomasson J, Gudjonsson T, et al. Lower extremity peripheral arterial disease in hospitalized patients with coronary artery disease. Vasc Med 2003;8:233-6.

9. Poredoš P, Jug B. The prevalence of peripheral arterial disease in high risk subjects and coronary or cerebrovascular patients. Angiology 2007;58:309-15.

10. Anand SS, Bosch J, Eikelboom JW, et al. Rivaroxaban with or without aspirin in patients with stable peripheral or carotid artery disease: an international, randomised, double-blind, placebocontrolled trial. Lancet 2018;391:219-29.

11. Jernberg T, Attebring MF, Hambraeus $\mathrm{K}$, et al. The Swedish Websystem for enhancement and development of evidence-based care in heart disease evaluated according to recommended therapies (SWEDEHEART). Heart 2010;96:1617-21.

12. Fowkes FGR, Rudan D, Rudan I, et al. Comparison of global estimates of prevalence and risk factors for peripheral artery disease in 2000 and 2010: a systematic review and analysis. Lancet 2013;382:1329-40.

13. Bonaca MP, Bhatt DL, Storey RF, et al. Ticagrelor for prevention of ischemic events after myocardial infarction in patients with peripheral artery disease. J Am Coll Cardiol 2016;67:2719-28.

14. Hiatt WR, Fowkes FGR, Heizer G, et al. Ticagrelor versus clopidogrel in symptomatic peripheral artery disease. N Engl J Med 2017;376:32-40.

15. Dinser $L$, Meisinger $C, A m a n n ~ U$, et al. Peripheral arterial disease is associated with higher mortality in patients with incident acute myocardial infarction. Eur J Intern Med 2018;51:46-52.

16. Banerjee A, Fowkes FG, Rothwell PM, et al. Associations between peripheral artery disease and ischemic stroke: implications for primary and secondary prevention. Stroke 2010;41:2102-7.

17. Inglis SC, Hermis A, Shehab S, et al. Peripheral arterial disease and chronic heart failure: a dangerous mix. Heart Fail Rev 2013;18:457-64.

18. Norgren L, Hiatt WR, Dormandy JA, et al. Inter-Society consensus for the management of peripheral arterial disease (TASC II). J VasC Surg 2007;45 Suppl S:S5-S67.

19. Tierney S, Mamas M, Skelton D, et al. What can we learn from patients with heart failure about exercise adherence? A systematic review of qualitative papers. Health Psychol 2011;30:401-10.

20. Baumann $F$, Husmann M, Benenati JF, et al. Bleeding risk profile in patients with symptomatic peripheral artery disease. J Endovasc Ther 2016;23:468-71. 